\title{
UMA ABORDAGEM NO ENSINO DA DISCIPLINA DE INFORMÁTICA E SOCIEDADE EM UM CURSO DE CIÊNCIA DA COMPUTAÇÃO: O RELATO DE UMA EXPERIÊNCIA ${ }^{1}$
}

\author{
Rodrigo Duarte Seabra
}

\begin{abstract}
RESUMO
Este trabalho apresenta uma proposta de abordagem no ensino da disciplina de Informática e Sociedade presente nas diretrizes curriculares da maioria dos cursos de Computação e afins. O objeto de estudo refere-se ao curso oferecido aos discentes da Universidade Federal de Itajubá em 2015. O artigo apresenta uma síntese dos principais tópicos debatidos nas aulas, bem como os resultados obtidos com base em uma investigação realizada junto aos discentes, sendo os mais notáveis sumarizados: (i) $96 \%$ dos estudantes relataram que a disciplina contribuiu na aquisição de conhecimento relevante para sua futura prática profissional; (ii) os temas informática na educação, regulamentação da profissão de tecnologia da informação, computação verde, computação ubíqua e evolução dos crimes cibernéticos foram os assuntos de maior destaque quanto aos aspectos sociais envolvidos no uso da informática.
\end{abstract}

Palavras-chave: Ciência da computação. Informática e sociedade. Ensino.

\section{INTRODUÇÃO}

Atualmente, a disciplina de Informática e Sociedade encontra-se inserida na maioria das matrizes curriculares de cursos de Ciência da Computação, Sistemas de Informação e afins. Neste contexto, por se tratar de um assunto cujo objetivo principal é discutir temas que contemplam os aspectos sociais, econômicos, legais e profissionais de computação, além do mercado de trabalho e as aplicações da tecnologia e sua constante evolução, na prática, observa-se que o enfoque utilizado pelos docentes em sala de aula versa sobre as mais variadas abordagens. Ademais, normalmente, esta disciplina é ministrada nos últimos períodos letivos dos cursos de computação, momento este em que o discente encontra-se na fase final de seu processo de formação na graduação. Isso reflete a necessidade de se utilizar abordagens atualizadas que possam contribuir no processo de ensino e aprendizagem, bem como motivar o aluno na etapa final de sua trajetória acadêmica, na condição de graduando.

\footnotetext{
${ }^{1}$ Como citar este artigo:

SEABRA, Rodrigo Duarte. Uma abordagem no ensino da disciplina de informática e sociedade em um curso de ciência da computação: o relato de uma experiência. ForScience: revista científica do IFMG, Formiga, v. 5 , n. 1, e00172, jan./jun. 2017.

${ }^{2}$ Doutor em Engenharia pela Escola Politécnica da Universidade de São Paulo (2009).

(http://lattes.cnpq.br/1450824752280712).E-mail: rodrigo@unifei.edu.br.

ForSci.: r. cient. IFMG, Formiga, v.5, n.1, e00172, jan./jun. 2017.
} 
Em linhas gerais, os Projetos Pedagógicos dos Cursos (PPCs) da área estabelecem temas norteadores para a condução desta e de outras disciplinas com base no currículo de referência (SBC, 2005) da Sociedade Brasileira de Computação, que, no caso da Informática e Sociedade, resumidamente, podem ser sintetizados como: (i) Aspectos Sociais, Econômicos, Legais e Profissionais de Computação; (ii) Mercado de Trabalho; (iii) Aplicações da Computação; (iv) Previsões de Evolução da Computação; (v) Ética Profissional; (vi) Segurança; (vii) Privacidade; (viii) Direitos de Propriedade; (ix) Acesso não Autorizado; (x) Códigos de Ética Profissional; (xii) Doenças Profissionais, dentre outros.

Dada a dinamicidade inerente à área e o fato de a computação encontrar-se inserida nas mais variadas atividades humanas, cada vez mais a formação do profissional da computação deve ser atualizada e sincronizada com a evolução da tecnologia, que se constitui em um dos objetos principais de estudo. Além disso, sobretudo em tempos atuais, a computação requer profissionais que se adaptem, de forma crítica, às novas situações às quais constantemente estão expostos.

Com base nessas considerações, o artigo propõe o uso de uma abordagem sob a ótica do ensino da disciplina de Informática e Sociedade no âmbito da computação, buscando enfatizar temas atuais que possam contribuir para a inclusão dos discentes na esfera social em que estão direta ou indiretamente inseridos. $\mathrm{O}$ estudo apresenta uma pesquisa realizada junto aos discentes da referida disciplina ministrada no curso de Ciência da Computação da Universidade Federal de Itajubá (UNIFEI), Minas Gerais, com o objetivo de averiguar não só a aceitação desse público acerca dos assuntos abordados nas aulas, mas, principalmente, sua visão no que diz respeito às possíveis contribuições em sua formação.

\section{REFERENCIAL TEÓRICO}

\subsection{Relatos sobre o ensino de Informática e Sociedade}

$\mathrm{Na}$ literatura científica, há poucos estudos sistematicamente relatados sobre variadas abordagens atinentes ao ensino da disciplina de Informática e Sociedade em cursos de Computação e afins. Possivelmente, este fato possa ser atribuído ao caráter humanístico envolvido no conteúdo da disciplina, o que talvez não desperte o interesse de pesquisas mais aprofundadas, bem como propostas de ensino e abordagens mais inovadoras na área. Dentre os poucos trabalhos disponíveis, a maioria fora publicada há mais de dez anos, e, por razões 
óbvias, seus objetivos principais variam em relação à abordagem empregada nesta oportunidade, sobretudo, dada a evolução tecnológica vivenciada na última década. Por essa razão, a publicação deste artigo pode ser justificada pela experiência vivenciada a partir do uso de temas atualizados e debatidos em sala de aula, necessários à formação discente no que se refere ao ensino da disciplina em questão.

Com o objetivo de transpor a barreira existente entre teoria e prática, a pesquisa de Estevam (2001) apresenta uma experiência desenvolvida entre os anos de 1995 e 2000 com estudantes de Informática da Universidade Federal de Juiz de Fora (UFJF). A proposta defendida incitou uma postura proativa dos alunos, de forma a envolvê-los diretamente com a identificação de problemas existentes em seu entorno e, por conseguinte, elaborando soluções criativas para minimizar os problemas elicitados. Por meio de situações reais, os principais resultados oriundos da aplicação da proposta foram: o projeto de uma empresa júnior e a criação de alguns projetos de extensão, tais como um curso de montagem e manutenção de microcomputadores para a comunidade, um curso de informática para a terceira idade e, finalmente, um curso preventivo sobre a doença diabetes. Vale salientar que, já em 2001, a autora relata que a proposta não era totalmente inovadora, pois já existiam disciplinas que abrangiam conteúdos semelhantes aos propostos no estudo.

A pesquisa realizada por Santos (2005) defendeu a importância de ampliar o nível de participação dos estudantes ao propor atividades a serem realizadas em grupo, segundo o formato de seminários. Para tanto, a autora utilizou um ambiente computacional interativo a fim de verificar a participação e a interação entre os estudantes da disciplina de Informática e Sociedade do curso de Ciência da Computação da Universidade do Estado do Rio de Janeiro (UERJ). Como principal resultado, observou-se que a existência da ferramenta não favoreceu a participação e o compartilhamento das informações entre os membros das equipes, permitindo apenas um melhor acompanhamento das atividades realizadas ao longo do semestre. Ademais, a autora relata que, após a primeira semana de trabalho, os estudantes aparentemente preferiram os encontros face a face em sala de aula.

Cafezeiro (2006) também relata uma experiência vivenciada em 2006 na condução da disciplina de Informática e Sociedade na Universidade Federal Fluminense (UFF). Ao incluir discussões relacionadas aos impactos sociais do uso da tecnologia na formação dos estudantes do curso de Ciência da Computação, a autora explorou, principalmente, aspectos relacionados ao tema Sociedade da Informação, abrangendo apenas alguns dos temas apresentados na 
proposta deste artigo. O formato adotado para a condução da disciplina também utilizou como base grupos de discussões e apresentações de trabalhos no formato de seminários.

Quadros et al. (2011) apresentam uma reflexão sobre o uso do ensino a distância no Centro Federal de Educação Tecnológica Celso Suckow da Fonseca (CEFET-RJ), como ferramenta de auxílio para a condução de disciplinas em cursos superiores de Informática no Brasil e, como estudo de caso, dentre outras disciplinas, a Informática e Sociedade foi explorada na proposta em questão. Por se tratar de uma proposta inovadora, na época, segundo os autores, o impacto do uso desta modalidade não pode ser totalmente mensurado, apesar de os autores terem observado reações positivas nos estudantes.

A pesquisa de Pinto (2010), realizada no âmbito do ensino de disciplinas correlatas à Informática e Sociedade, tais como Tópicos de Formação Humanística e Ética em Computação, para alunos de Engenharia, visou à reflexão discente sobre a importância de estes se dedicarem às disciplinas ofertadas com foco em temas humanísticos. Além disso, o estudo discute um enfoque detalhado sobre o processo de resistência apresentado pelos estudantes às disciplinas de formação humanística, pautado por variados motivos: privilégio do conhecimento técnico-científico; fatores ambientais, culturais, econômicos e políticos; fatores psicológicos e biológicos; e fatores sociais, fortalecidos pelo enfraquecimento da comunicação face a face e a necessidade de reflexões sobre ética.

Com base no exposto, considerando os desafios do cidadão na sociedade contemporânea, representados, principalmente, pela desigualdade social, e outros potencializados pelo desenvolvimento tecnológico e pela globalização (PINTO, 2010), faz-se necessária uma abordagem atualizada dos tópicos tratados em disciplinas de formação humanística, neste caso, a disciplina de Informática e Sociedade, exercitando, sobretudo, a relação face a face dos estudantes.

\subsection{O ensino de Informática e Sociedade na UNIFEI}

A disciplina de Informática e Sociedade da UNIFEI é ministrada no sexto período dos cursos de Ciência da Computação e Sistemas de Informação. Nesta oportunidade, tomou-se como amostra para o estudo realizado as aulas proferidas aos alunos do curso de Ciência da Computação. Como a disciplina é semestral, o curso oferecido compreendeu três horas/aula semanais, perfazendo uma carga horária total de 48 horas. 
No âmbito do ensino e discussão da referida disciplina, nesta oportunidade, os discentes foram expostos a conteúdos ligados à atualidade, versando sobre dezoito temas. A seguir, são apresentados e discutidos, sumariamente, cada um dos temas abordados.

\subsection{Considerações sobre os temas abordados no curso}

Inúmeras pesquisas têm sido realizadas acerca da Informática na Educação, mediante a oportunidade de se utilizar recursos computacionais como forma de incentivar e motivar o estudante dentro e fora da sala de aula, bem como os benefícios proporcionados pelo uso da tecnologia nesse contexto (SEABRA, 2012). De modo geral, as pesquisas da área buscam a disseminação de ferramentas, métodos e práticas que auxiliam no uso efetivo dos recursos tecnológicos no processo de ensino e aprendizagem.

A exemplo da Educação, outra área em que o uso de tecnologias vem sendo amplamente explorado é a Medicina. Segundo Marques (2011), a área da saúde e a Computação têm gerado diversas ferramentas e ambientes computacionais em virtude dos trabalhos inter e multidisciplinares desenvolvidos nos últimos anos. Isso se reflete no uso de novas tecnologias de Processamento de Imagens e Realidade Virtual que, por meio de algoritmos e técnicas especializadas, proporcionam inovadoras possibilidades de desenvolvimento de sistemas, além de aspectos relacionados à interação, composição e visualização tridimensional de imagens.

Migrando da esfera educacional e médica, no sentido de promover cada vez mais a acessibilidade e a transparência e na tentativa de aproximar o governo e os cidadãos por meio de ferramentas eletrônicas e tecnologias da informação, surge em cena outro tema de relativa importância - o Governo Eletrônico ${ }^{3}$. Nessa seara, diferentes ferramentas podem ser exploradas, tais como portais de internet com fóruns, exposição de bancos de dados, aplicativos para telefonia móvel, dentre outros (GARCIA, 2006; CORREA, 2011).

Na atualidade, em função da difusão do acesso e do uso da internet, observa-se um aumento substancial nas transações comerciais realizadas por meio de equipamentos eletrônicos. Em linhas gerais, o comércio eletrônico faz uso de variados mecanismos que possibilitam sua realização, como, por exemplo, por meio de catálogos e leilões eletrônicos, clube de compras e compras coletivas. Essa prática comercial vem ganhando cada vez mais

\footnotetext{
${ }^{3}$ http://www.governoeletronico.gov.br/
} 
notoriedade e atraindo públicos das mais diversas faixas etárias (TURBAN; KING, 2004; ALBERTIN, 2010).

Outro assunto de significativa relevância versa sobre o uso da Tecnologia da Informação - que evoluiu de uma visão tradicional de suporte administrativo para um papel estratégico dentro das organizações - como ferramenta nos meios produtivos visando à obtenção de vantagem competitiva envolvendo aspectos humanos, administrativos e organizacionais. Nesse cenário, destaca-se o uso de sistemas de informação, tais como os sistemas Enterprise Resource Planning - ERP (BIANCOLINO, 2010), Supply Chain Management - SCM (MENTZER, 2001) e Customer Relationship Management - CRM (PAYNE; FROW, 2005), além de sistemas que apoiam os processos de análise e tomada de decisão - Business Intelligence - BI (WATSON; WIXOM, 2007).

$\mathrm{Na}$ esfera dos negócios e explorando modelos de arquiteturas orientadas a serviços, os serviços web se apresentam e se consolidam cada vez mais como um alicerce de novas oportunidades. Idealmente, essa tecnologia é vista como uma forma de expor determinadas funcionalidades - desde simples requisições até a execução de processos de negócios complexos - de sistemas na Internet com o uso de padrões de comunicação que, por sua vez, diminuem a heterogeneidade e a complexidade de integração dos serviços. Um exemplo de abordagem em relação ao uso dessa tecnologia pode ser encontrado em (YU, 2007).

Ainda no contexto da Internet, emerge outro tema de destaque - a Web Semântica (ISOTANI, 2009). O objetivo principal das aplicações com características semânticas é determinar os significados de textos e dados, criando conexões para os usuários. Os conceitos abstratos envolvidos nessa tecnologia proporcionam aos usuários a capacidade de criar repositórios de dados na rede, além de construir vocabulários e escrever regras para interoperarem com esses dados. Com isso, as informações publicadas na rede passam a apresentar sentido ao serem conectadas a partir de uma semântica e, por conseguinte, tornando-se legíveis para as máquinas.

Provavelmente, um dos temas mais polêmicos, a regulamentação da profissão de TI, engloba debates sobre variados aspectos que vão desde as vantagens em se criar um Conselho da Profissão de Informática até a necessidade da comprovação de diploma de curso superior em Informática no exercício de atividades profissionais do setor. Por se tratar de um assunto estritamente ligado à atuação profissional, observa-se uma carência de abordagens e debates 
científicos em torno do tema. Inúmeros questionamentos envolvendo o tema $\mathrm{e} o$ posicionamento da SBC em torno dele podem ser consultados no site ${ }^{4}$ da sociedade científica.

No que tange aos trabalhos e à cooperação realizados em grupo, prática extensamente explorada na computação, os sistemas colaborativos se apresentam como ferramentas de software que visam facilitar a execução de tarefas por meio de formas de interação que facilitem o controle, a coordenação, a colaboração e a comunicação entre os indivíduos envolvidos, estejam eles no mesmo local ou geograficamente dispersos. A recente obra de (PIMENTEL; FUKS, 2010) retrata variados tipos de sistemas que oferecem suporte ao trabalho colaborativo e discute os aspectos sociais relacionados ao uso, bem como os aspectos técnicos referentes ao desenvolvimento dessa categoria de sistema.

Além da evolução verificada no que concerne aos aspectos tecnológicos, é notável também a alteração do perfil dos profissionais atuantes na área, sobretudo, em função das exigências e necessidades das empresas. Isso se deve, principalmente, às inovações inerentes aos negócios. Assim, na atualidade, o profissional de TI é o resultado da soma de variadas parcelas, que contemplam habilidades técnicas e de negócio, abrangendo, inclusive, capacidades de relacionamento interpessoal. Tal fato evidencia a oportunidade de se abordar em sala de aula as principais características desejáveis do novo perfil profissional da área em um cenário de constantes mudanças, além dos recentes papéis assumidos pelos indivíduos no contexto empresarial, por exemplo, analistas de desenvolvimento/infraestrutura/Business Intelligence, analistas de negócios/processos, gerente de projetos, administradores de redes, Chief Information Officer (CIO) ou gerente de TI, dentre outros. Pode-se citar como exemplo de trabalho relativo ao perfil do profissional de TI a pesquisa de (GAVIOLI, 2009).

Ao se falar em evolução do perfil profissional e da tecnologia, mais especificamente na disseminação da internet como instrumento de acesso, em alguns casos, as informações sigilosas, abre-se espaço para a abordagem de problemas decorrentes deste cenário. À medida que a tecnologia, os meios de acesso e as medidas preventivas evoluem, novos métodos criativos para burlar os mecanismos de proteção são descobertos. Neste momento, surge em pauta outro tema interessante de debate - a evolução dos crimes cibernéticos. No Brasil, podem-se encontrar inúmeros exemplos de estudos nesse campo publicados não só, mas, principalmente, nos anais da Conferência Internacional de Perícias em Crimes Cibernéticos 5 . Além disso, nesse campo, destaca-se também a obra de (STALLINGS, 2007).

\footnotetext{
${ }^{4}$ http://www.sbc.org.br/

5 http://www.iccyber.org/
} 
Outros exemplos de problemas resultantes do processo evolutivo da tecnologia dizem respeito à fabricação, ao consumo de energia elétrica e, principalmente, à produção de lixo eletrônico, ou seja, o descarte de peças e equipamentos eletrônicos. Em virtude dos materiais pesados constituintes da composição desses componentes, caso o descarte não seja feito levando-se em conta aspectos de sustentabilidade, danos ambientais podem ser gerados. No que se refere a este assunto, um conjunto de práticas e medidas - denominado Computação Verde - tem sido debatido no sentido de tornar o uso da computação mais sustentável, diminuindo os malefícios relativos à operação dos computadores (MANN; SMITH; MULLER, 2008).

No sentido de contribuir para a preservação e o uso racional dos recursos naturais, pode-se destacar como uma tendência recente o conceito de Computação em Nuvem, que permite ao usuário explorar as capacidades de armazenamento e cálculo de computadores e servidores compartilhados e interligados pela Internet. Dentre as pesquisas brasileiras recentes sobre o tema, encontram-se as de (OGURA, 2011; RAMALHO, 2012).

Seguindo as tendências da evolução tecnológica, segundo Benyon (2011), os sistemas de computação estão se tornando cada vez mais ubíquos, pois são carregados, vestidos e incorporados a todo tipo de dispositivo. O desafio presente nessa tecnologia reside no fato do que variados dispositivos podem fazer e com quais outros podem se comunicar, o que caracteriza espaços de informação distribuídos. Ainda de acordo com o autor, a tarefa de navegação nos ambientes ubíquos exige novas ferramentas que apresentem informação sobre os objetos, utilizando técnicas como a Realidade Aumentada (RA). No que se refere à RA, destaca-se o trabalho recente de (KIRNER, 2011).

No contexto da mobilidade, a computação móvel, que abrange desde telefones celulares a pequenos computadores notebooks, palmtops, assistentes pessoais digitais e leitores de $e$-books (FORMAN; ZAHORJAN, 1994), se apresenta como um novo paradigma computacional que predominará cada vez mais no futuro. Em linhas gerais, trata-se de um conceito pautado por três características - processamento, mobilidade e comunicação sem fio - que ampliam o conceito tradicional de computação distribuída.

Outro tema de cunho tecnológico abordado no curso envolveu um debate sobre os aspectos inovadores aplicados na análise de um volume inédito de dados digitais disponíveis no cenário atual, denominados, convencionalmente, de Big Data (AGRAWAL; DAS; ABBADI, 2011). Em função da exacerbada produção de informação nos mais variados setores, os computadores acompanharam esse fenômeno e passaram a interpretar grandes 
volumes de dados cujo interesse se aplica a companhias que vão desde o varejo e o setor financeiro ao de petróleo e gás. Como exemplo, alguns varejistas americanos têm coletado dados online de potenciais consumidores com o objetivo de impulsionar as vendas de suas lojas físicas. Os softwares explorados nesse contexto monitoram determinadas discussões e opiniões, sobretudo nas redes sociais, acerca de um assunto em determinada região e, em pouco tempo, os gerentes das lojas situadas no entorno expõem em suas vitrines produtos relativos aos comentários. Vale destacar que boa parte dos dados processados é fruto de insumos representados pelas informações pessoais disponíveis na internet por parte de seus bilhões de usuários.

No cenário profissional em TI, muito se fala sobre a adoção de mecanismos de segurança para computadores e aspectos ligados ao ambiente físico em detrimento das condições de trabalho oferecidas aos funcionários que, por sua vez, se constituem no principal recurso. Em uma área que apresenta comportamento extremamente dinâmico, determinadas pressões inerentes ao cumprimento de prazos, acompanhamento das mudanças e evoluções tecnológicas e exigência de produtividade, aliadas às preocupações tradicionais da maioria dos trabalhadores das mais variadas áreas, relativas à empregabilidade em um mercado cada vez mais competitivo e bons relacionamentos no ambiente de trabalho, podem se apresentar como fatores cruciais para o desencadeamento de enfermidades. Com o passar do tempo, essas sobrecargas podem causar danos à saúde do trabalhador, apresentando-se na forma de diferentes doenças. Nesse sentido, deve-se investir em melhorias no ambiente físico, bem como em treinamentos para a prevenção de doenças e lesões ocupacionais, como, por exemplo, por meio de ginástica laboral. Apesar de a maioria delas ser causada no exercício da profissão, nem sempre as enfermidades que acometem o trabalhador podem ser atribuídas ao empregador; pelo contrário, alguns pontos são de responsabilidade do profissional e podem ser evitados quando se exerce a profissão de modo saudável. No que se refere à atividade profissional de TI, podem-se destacar as principais doenças: LER (Lesão por Esforço Repetitivo), doenças oculares, ósseas e articulares e estresse (ALVAREZ, 2002).

Além das doenças destacadas, uma vasta incidência de retaliações oriundas do uso da tecnologia também é verificada na atualidade, caracterizando um termo recentemente novo para a sociedade - o Bullying Virtual (ou, do inglês, Cyberbullying). O termo refere-se a atos de violência psicológica que ocorrem em meios eletrônicos, intencionais e repetidos, sem motivações específicas, praticados por um ou mais indivíduos no sentido de, em sua maioria, amedrontar, intimidar e/ou agredir pessoas incapazes de se defenderem. A maioria das 
situações que respaldam a prática do bullying envolve mensagens difamatórias, ameaçadoras e discriminantes que circulam por e-mails, redes sociais, blogs, sites e celulares. Tal prática ganha força e se sustenta em função de exposições cada vez maiores na internet. Por intermédio do anonimato proporcionado por ela, as abordagens podem ser intensificadas, proporcionando efeitos graves não só, mas, sobretudo, em crianças e adolescentes (AMADO, 2009).

Em síntese, esta seção buscou apresentar, resumidamente, os principais aspectos norteadores das discussões e debates promovidos nas aulas em cada tema citado. A próxima seção abrange a pesquisa realizada com base nas informações coletadas junto aos discentes do curso.

\section{MÉTODO}

\subsection{Participantes e aplicação da investigação}

A investigação relata a experiência de avaliação da opinião dos estudantes do curso de Ciência da Computação após frequentarem as aulas da disciplina de Informática e Sociedade na UNIFEI, no ano de 2014. Na apresentação inicial da disciplina, no primeiro encontro presencial, que abrangeu a discussão do plano de ensino e dos tópicos a serem abordados no curso, a turma foi dividida em equipes para o desenvolvimento dos estudos exploratórios e preparação de artigos e seminários resultantes do trabalho de pesquisa, totalizando nove grupos. Os temas foram sorteados dentre as equipes, sendo que cada uma ficou responsável por dois temas distintos. Nesse contexto, os assuntos dos seminários se distribuíram entre os dezoito temas principais das aulas teóricas, com o objetivo de fazer os alunos identificarem e ressaltarem os aspectos sociais envolvidos no uso da informática. Assim, cada equipe buscou as novidades tecnológicas e a sua aplicação no âmbito social do uso da tecnologia. Semanalmente, após a apresentação do seminário de cada grupo, promoveu-se um debate sobre os aspectos explanados. Finalmente, na última semana de aula, foi aplicada a avaliação da disciplina que versou sobre o conteúdo teórico e os resultados apresentados em forma de artigos e seminários.

Após a realização da avaliação final da disciplina e no que tange ao objetivo principal deste trabalho, vinte e oito estudantes de graduação responderam a um instrumento de coleta de dados composto por quatro questões.

ForSci.: r. cient. IFMG, Formiga, v.5, n.1, e00172, jan./jun. 2017. 


\subsection{Resultados e Discussão}

A primeira questão investigada junto aos discentes envolveu as possíveis contribuições oferecidas pela disciplina na aquisição de conhecimento relevante para sua futura prática profissional. Nesse cenário, apenas um aluno considerou que o curso não promoveu contribuição nesse sentido, conforme se observa no discurso transcrito ipsis litteris, a seguir:

A matéria abordou diversos temas interessantes, mas uma vez que estamos no $5^{\circ}, 6^{\circ}$, $7^{\circ}$ semestre de computação já estamos acostumados com eles todos.

Com base no discurso anterior, o autor desta pesquisa ressalta que a opinião possivelmente reflita a falta de compreensão do aluno quanto ao objetivo principal da disciplina, a saber: capacitar o aluno a identificar o impacto da utilização de computadores na sociedade e no indivíduo, ampliando o seu conceito de Cidadania, Ética e Responsabilidade Social. Contrariamente à opinião expressa, a intenção dos assuntos trabalhados no curso não visava ao ineditismo, mas, sim, ao destaque dos aspectos sociais envolvidos em cada tema, além dos impactos promovidos pelo uso da tecnologia no contexto social. Essa visão é corroborada pela opinião dos demais participantes da pesquisa, conforme se observa em outros comentários:

A disciplina abre a nossa mente para assuntos que fogem do escopo do curso, mas que também estão intimamente ligados a ele.

Apesar de alguns temas já estarem batidos, como os crimes cibernéticos aparentemente já de conhecimento geral, as discussões promovidas ao final da apresentação, creio ser o ponto alto dos temas, porque é onde vemos a opinião dos outros e de certa forma repensamos as nossas.

A próxima questão de pesquisa investigada procurou identificar os cinco temas mais relevantes quanto aos aspectos sociais envolvidos no uso da informática. Para essa questão, foram documentados 140 registros, distribuídos nos dezoito temas abordados no curso, conforme se observa na Figura 1. Os temas representados correspondem a: (1) Informática na Educação; (2) Informática na Medicina; (3) Governo Eletrônico; (4) Comércio Eletrônico; (5) Impacto da Informática sobre os Meios Produtivos; (6) Regulamentação da Profissão de TI; (7) Sistemas Colaborativos; (8) Evolução do Perfil do Profissional de TI; (9) Evolução dos Crimes Cibernéticos; (10) Computação Verde; (11) Computação em Nuvem; (12) 
Computação Ubíqua; (13) Serviços Web; (14) Web Semântica; (15) Computação Móvel; (16)

Big Data; (17) Principais Doenças Profissionais; e (18) Bullying Virtual.

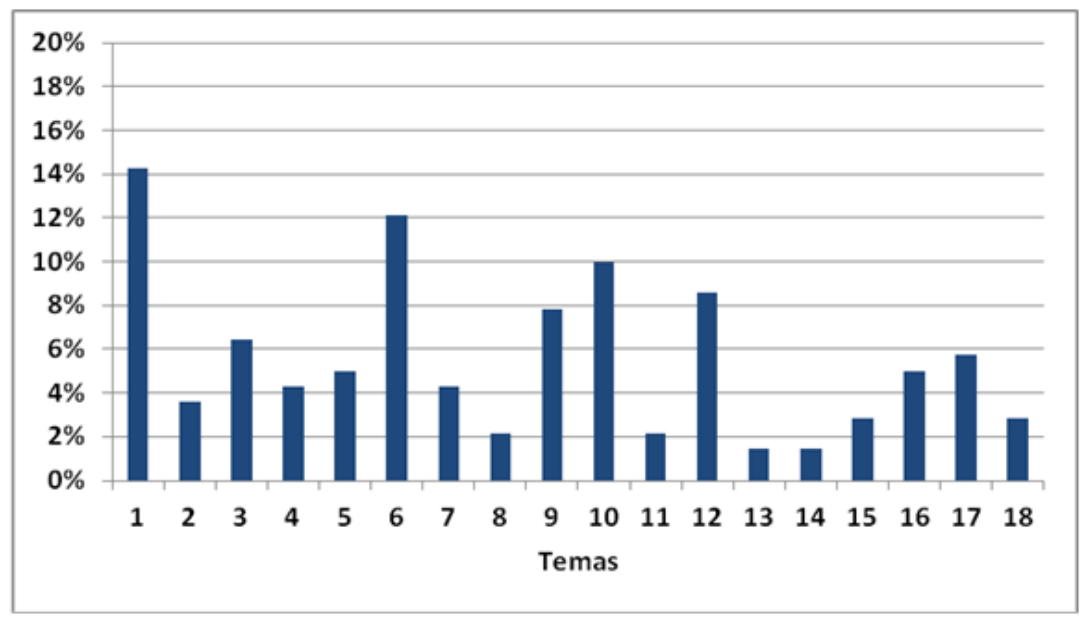

Figura 1 - Produtividade dos temas segundo a relevância dos aspectos sociais envolvidos no uso da informática.

Fonte: Do autor (2017).

Com base na distribuição, observa-se que a resposta mais produtiva, no universo de todas as opiniões, corresponde ao tema 1 - Informática na Educação, que representa 14,29\% da amostra, seguida de 6 - Regulamentação da Profissão de TI (12,14\%), 10 - Computação Verde (10\%), 12 - Computação Ubíqua (8,57\%), e 9 - Evolução dos Crimes Cibernéticos $(7,86 \%)$. Com menos de $2 \%$ de representatividade, foram documentados os temas 13 Serviços Web e 14 - Web Semântica.

O tema Informática na Educação apresentou-se como o mais produtivo, provavelmente em virtude das variadas oportunidades de inserção da informática como forma de contribuir no processo de ensino-aprendizagem, o que reflete benefícios diretos à sociedade. Além de se caracterizar no tema de maior repercussão, segundo a opinião dos participantes, foi sugerido um maior destaque no assunto, conforme se observa no discurso a seguir:

Eu acho que seria muito interessante dar um enfoque maior a informática na educação, pois foi o tema que mais me interessou. Talvez fazer com que os alunos reflitam sobre os meios de usar melhor o computador para distribuir conhecimento será muito produtivo.

Sobre o segundo tema mais relevante - Regulamentação da Profissão de TI verificou-se que, para alguns alunos, a disciplina proporcionou a primeira oportunidade de contato com o assunto, o que talvez tenha refletido um alto índice de aprovação segundo o 
critério de relevância. Isso pode ser corroborado pelos relatos de dois participantes que escolheram o referido tema como um dos cinco mais relevantes:

Após 3 anos na Universidade, alguns temas só tive conhecimento esse semestre, como regulamentação da profissão, que está diretamente ligado ao nosso futuro como profissional.

A matéria acrescentou conhecimento de assuntos que eu não sabia nem mesmo o que eram, como a computação ubíqua, sistemas colaborativos e regulamentação da profissão de TI.

Questionados sobre outros possíveis assuntos interessantes a serem debatidos na disciplina, as opiniões versaram, de modo geral, sobre: (i) Inclusão Digital; (ii) Impacto da Internet e Ferramentas Sociais no Comportamento das Massas; (iii) Impacto dos Jogos Digitais na Sociedade; (iv) Deep Web; (v) Áreas de Atuação do Profissional de TI; (vi) Pirataria e suas Consequências; (vii) Software Livre e Democratização de Acesso; (viii) Transporte, Sociedade e Computação; (ix) Softwares para Deficientes.

Especificamente para a sugestão (v) Áreas de Atuação do Profissional de TI, chama a atenção os comentários de dois participantes:

\footnotetext{
Apesar de esta ser uma disciplina de último ano, vejo muita gente perdida. Sim, a área de atuação com certeza é a informática e gosto de programar, mas e aí, qual o próximo passo? Uma visão e orientação, até de quem já se formou seria muito interessante para o curso.

Creio que caberia na matéria discutir sobre que carreira (áreas de atuação) um formando do curso poderia seguir, sinto falta dessa questão no curso.
}

Os relatos anteriores revelam a insegurança, a ansiedade e a preocupação inerentes aos alunos que, apesar de em breve gozarem dos possíveis benefícios proporcionados por uma capacitação em nível superior, tentarão ingressar em um mercado de trabalho altamente competitivo e exigente. Tais opiniões evidenciam a necessidade de os docentes trabalharem com seus alunos aspectos ligados, sobretudo, à formação profissional contínua, se considerarmos o dinamismo da computação e seus possíveis direcionamentos com base na vocação e interesse demonstrados por cada estudante.

Finalmente, a última questão do estudo buscou realizar uma avaliação da disciplina no que se refere a sua contribuição na formação discente. A Figura 2 revela a opinião dos alunos em relação a esse quesito. A distribuição dos dados ressalta a boa aceitação da disciplina quanto ao seu papel na formação do estudante. Sabe-se que, em geral, os discentes de cursos 
com foco tecnológico escolhem a área devido ao interesse e ao contato constante com assuntos inerentes ao funcionamento da tecnologia, além de processos de desenvolvimento e inovação. Não menos importante, as disciplinas de cunho humanístico e complementar proporcionam ao egresso uma dimensão social e humana, por meio do tratamento de temas como o empreendedorismo, a ética em computação, a interação com profissionais de outras áreas na busca de soluções computacionais para seus problemas, dentre outros. Com isso, para alguns, essas disciplinas acabam sendo encaradas como uma mera obrigação, cabendo ao docente responsável por elas o desafio de utilizar abordagens diferenciadas no sentido de despertar o interesse dos alunos pelos assuntos tratados, destacando, assim, a sua importância no processo de formação.

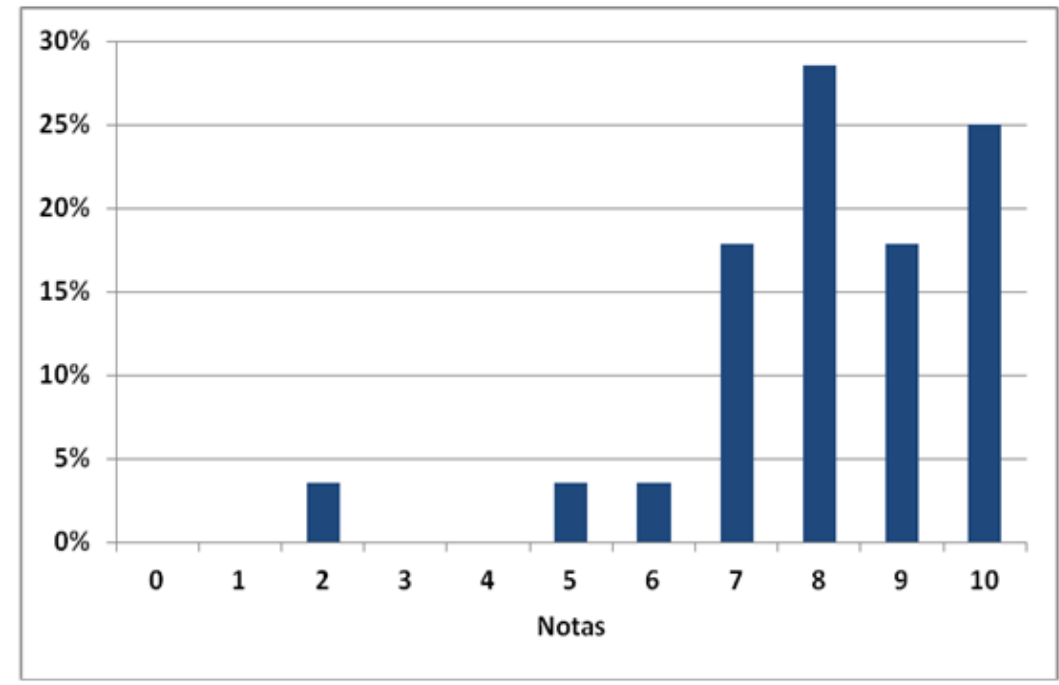

Figura 2 - Avaliação da disciplina quanto a sua contribuição na formação Fonte: Do autor (2017). segundo a opinião dos participantes.

No contexto desta pesquisa, fica claro que a disciplina alcançou seu objetivo.

\section{CONCLUSÃO}

A Ciência da Computação e sua aplicação social nas variadas áreas do conhecimento têm um impacto ímpar na sociedade. As oportunidades mercadológicas são cada vez mais animadoras, e a falta de profissionais qualificados é um fato. Nesse cenário, verifica-se a necessidade de se explorar abordagens atualizadas em sala de aula no sentido de mostrar aos estudantes, sobretudo aqueles que se encontram na etapa final do curso, as inúmeras possibilidades de atuação e os potenciais para melhoria das tecnologias existentes. 
Com base nos resultados coletados neste estudo, considera-se que, na experiência de ensino apresentada, foram desenvolvidas situações que levaram o aluno à reflexão de seu papel social no futuro exercício de sua prática profissional. Por meio do pensamento crítico e do conteúdo teórico abordado e sua apropriação desenvolvida nos seminários e debates promovidos em sala de aula, os estudantes puderam vislumbrar oportunidades nas quais o uso da tecnologia é não somente uma realidade, mas também uma necessidade. Acredita-se que o uso de abordagens contextualizadas propicia uma visão aplicada de conteúdos teóricos aprendidos e motiva os discentes frente ao seu ingresso no mercado de trabalho.

\title{
AN APPROACH IN TEACHING OF THE DISCIPLINE INFORMATICS AND SOCIETY IN A COMPUTER SCIENCE COURSE: REPORTING AN EXPERIENCE
}

\begin{abstract}
This paper presents a proposal for an approach in the teaching of the discipline Informatics and Society, which is present in the curriculum guidelines of most Computing and related courses. The object of study refers to the course offered to students of the Federal University of Itajubá in 2014. The research presents a summary of the main topics discussed in classes as well as the results obtained with basis on an investigation carried out with the students and the most notably summarized: (i) $96 \%$ of the students reported that the discipline contributed to the acquisition of relevant knowledge to their future professional practice; (ii) informatics in education issues, regulation of information technology profession, green computing, ubiquitous computing and evolution of cybercrimes were the most prominent themes regarding the social aspects involved in the use of information technology.
\end{abstract}

Keywords: Computer Science. Informatics and Society. Teaching.

\section{REFERÊNCIAS}

AGRAWAL, D.; DAS, S.; ABBADI, A. Big data and cloud computing: current state and future opportunities. In: INTERNATIONAL CONFERENCE ON EXTENDING DATABASE TECHNOLOGY. 14., 2011, Uppsala, Sweden. Proceedings... New York: ACM, 2011. p. 530-533.

ALBERTIN, A. L. Comércio eletrônico: modelo, aspectos e contribuições de sua aplicação. 6. ed. São Paulo: Atlas, 2010.

ALVAREZ, B. R. Estilo de vida e hábitos de lazer de trabalhadores, após dois anos de aplicação de um programa de ginástica laboral e saúde. 2002. 172 f. Tese (Doutorado em Engenharia de Produção) - Centro Tecnológico, Universidade Federal de Santa Catarina, Florianópolis, 2002. 
AMADO, J. et al. Cyberbullying: um desafio à investigação e à formação. Revista Interacções, n. 13, p. 301-326, 2009.

BENYON, D. Interação humano-computador. 2. ed. São Paulo: Pearson Prentice-Hall, 2011. $442 \mathrm{p}$.

BIANCOLINO, C. A. Valor de uso do ERP e gestão contínua de pós-implementação: estudo de casos múltiplos no cenário brasileiro. 2010. 502 f. Tese (Doutorado em Controladoria e Contabilidade: Contabilidade) - Faculdade de Economia, Administração e Contabilidade, Universidade de São Paulo, São Paulo, 2010.

CAFEZEIRO, I. Educação, informática e responsabilidade social: a contribuição da universidade pública. In: SIMPÓSIO BRASILEIRO DE INFORMÁTICA NA EDUCAÇÃO. 17., 2006, Brasília. Anais... Brasília: UNB/UCB, 2006. p. 21-30.

CORREA, D. O. X-gov: planejamento de serviços eletrônicos de governo usando mídias cruzadas. 2011. 242 f. Dissertação (Mestrado em Sistemas Digitais) - Escola Politécnica, Universidade de São Paulo, São Paulo, 2011.

ESTEVAM, R. C. O. A experiência de uma disciplina socialmente pró-ativa: informática \& sociedade. In: WORKSHOP SOBRE EDUCAÇÃO EM COMPUTAÇÃO. 9., 2001, Fortaleza. Anais... Fortaleza: BDB Comp, 2001.

FORMAN, G. H.; ZAHORJAN, J. The challenges of mobile computing. Computer, v. 27, n. 4, p. 38-47, 1994.

GARCIA, R. M. Governo eletrônico, informação e competência em informação. Informação \& Sociedade: Estudos, v. 16, n. 2, p. 79-87, 2006.

GAVIOLI, E. S. Uma contribuição para o delineamento do perfil do profissional de TI frente aos papéis exercidos durante o processo de desenvolvimento de software. 2009. 197 f. Dissertação (Mestrado em Tecnologia: Gestão, Desenvolvimento e Formação) - Centro Estadual de Educação Tecnológica Paula Souza, CEETEPS, São Paulo, 2009.

ISOTANI, S. et al. Estado da arte em web semântica e web 2.0: potencialidades e tendências da nova geração de ambientes de ensino na internet. Revista Brasileira de Informática na Educação, v. 17, n. 1, 2009.

KIRNER, C. et al. Using augmented reality to support the understanding of three-dimensional concepts by blind people. International Journal on Disability and Human Development, v. 10, p. 1-8, 2011.

MANN, S.; SMITH, L.; MULLER, L. Computing education for sustainability. ACM SIGCSE Bulletin, v. 40, n. 4, p. 183-193, 2008.

MARQUES, F. L. S. N. Processamento gráfico para aplicações em saúde: técnicas, requisitos, ferramentas, desafios e oportunidades. 2011. 153 f. Tese (Livre Docência em Ciência da Computação) - Escola de Artes, Ciências e Humanidades, Universidade de São Paulo, São Paulo, 2011. 
MENTZER, J. T. et al. Defining Supply Chain Management. Journal of Business Logistics, v. 22, n. 2, p. 1-25, 2001.

OGURA, D. R. Uma metodologia para caracterização de aplicações em ambientes de computação nas nuvens. 2011. 124 f. Dissertação (Mestrado em Sistemas Digitais) - Escola Politécnica, Universidade de São Paulo, São Paulo, 2011.

PAYNE, A.; FROW, P. A strategic framework for customer relationship management. Journal of Marketing, v. 69, n. 4, p. 167-176, 2005.

PIMENTEL, M.; FUKS, H. Sistemas colaborativos. Rio de Janeiro: Elsevier, 2010.

PINTO, G. R. P. R. Disciplinas humanísticas na formação do engenheiro: fatores de resistência dos estudantes e estratégia educacional para a sua motivação. 2010. $284 \mathrm{f}$. Tese (Doutorado em Educação) - Universidade Federal da Bahia, Salvador, 2010.

QUADROS, J. R. T. et al. O ensino a distância pela internet como ferramenta de auxílio em um curso superior de informática. In: CONGRESSO BRASILEIRO DE ENSINO SUPERIOR A DISTÂNCIA. 8., 2011, Ouro Preto. Anais... Ouro Preto: UNIREDE, 2011.

RAMALHO, N. C. L. Um estudo sobre a adoção da computação em nuvem no Brasil. 2012. 157 f. Dissertação (Mestrado em Sistemas de Informação) - Escola de Artes, Ciências e Humanidades, Universidade de São Paulo, São Paulo, 2012.

SANTOS, N. Avaliação da participação de estudantes em seminários em grupo. In: SIMPÓSIO BRASILEIRO DE INFORMÁTICA NA EDUCAÇÃO. 16., 2005, Juiz de Fora. Anais... Juiz de Fora: UFJF, 2005. p. 5-8.

SOCIEDADE BRASILEIRA DE COMPUTAÇÃO. Currículo de Referência da SBC para Cursos de Graduação em Bacharelado em Ciência da Computação e Engenharia da Computação - versão 2005. Porto Alegre, 2005.

SEABRA, R. D. Pesquisa experimental para análise do desenvolvimento da habilidade de visualização espacial em ferramenta inovadora de realidade virtual para o ensino de geometria descritiva. Educação Gráfica, v. 16, p. 23-40, 2012.

STALLINGS, W. Criptografia e segurança de redes: princípios e práticas. 4. ed. São Paulo: Pearson Prentice-Hall, 2007.

TURBAN, E.; KING, D. Comércio eletrônico: estratégia e gestão. São Paulo: Prentice Hall, 2004.

WATSON, H. J.; WIXOM, B. H. The current state of Business Intelligence. Computer, v. 40, n. 9, p. 96-99, 2007.

YU, T.; ZHANG, Y.; LIN, K. Efficient algorithms for web services selection with end-to-end QoS constraints. ACM Transactions on the Web, v. 1, n. 1, p.6-es, 2007. 
Recebido em: 16/03/2016

Aprovado em: 09/03/2017

Publicado em: 31/03/2017

ForSci.: r. cient. IFMG, Formiga, v.5, n.1, e00172, jan./jun. 2017. 